\title{
SPEKTROSKOPI FOURIER TRANSFORM INFRA RED DENGAN METODE REFLEKTANSI (ATR-FTIR) PADA OPTIMASI PENGUKURAN SPEKTRUM VIBRASI VITAMIN C
}

\author{
Martin Sulistyani \\ Laboratorium Kimia FMIPA Universitas Negeri Semarang \\ Gedung D8 Kampus Sekaran Gunungpati Semarang 50229 \\ Email: mart.sulistyani@gmail.com
}

\begin{abstract}
Abstrak
Pengukuran spektrum vibrasi vitamin $\mathrm{C}$ dilakukan dengan menggunakan metode spektroskopi Fourier Transform Infra Red reflektansi (ATR-FTIR). Vitamin C memiliki karakteristik daerah serapan yang khusus sehingga serapan tersebut mewakili gugus fungsi yang ada pada vitamin $\mathrm{C}$. Spektrum vibrasi menunjukkan adanya ikatan gugus $\mathrm{C}-\mathrm{H}$, gugus $\mathrm{C}=\mathrm{O}$, gugus $\mathrm{C}=\mathrm{C}$, gugus $\mathrm{C}-\mathrm{O}-\mathrm{C}$, dan gugus $\mathrm{O}-\mathrm{H}$. Hasil pengukuran spektrum vitamin $\mathrm{C}$ menggunakan kuat tekan 80 (force gauge) menunjukkan absorbansi maksimal sebesar 0,0216 pada daerah bilangan gelombang $1320,14 \mathrm{~cm}^{-1}$. Hasil pengukuran spektrum vitamin $\mathrm{C}$ dengan waktu penekanan 30 detik menunjukkan absorbansi maksimal sebesar 0,0236 pada daerah bilangan gelombang 1319,37 $\mathrm{cm}^{-1}$. Hasil penelitian memberikan kontribusi untuk metode pengukuran menggunakan spektroskopi FT-IR sehingga mendapatkan spektra yang baik pada pengukuran spektroskopi FT-IR mode reflektansi (ATRFTIR) untuk karakterisasi produk penelitian. Metode yang digunakan adalah teknik analisis vibrasi molekul untuk menentukan gugus fungsi menggunakan spektroskopi FT-IR mode reflektansi (ATR-FTIR) dengan membandingkan spektrum pembacaan pellet sampel vitamin $\mathrm{C}-\mathrm{KBr}$ dan mengeinterpretasi spektra yang dihasilkan.
\end{abstract}

Kata Kunci: FTIR, metode reflektansi, pengukuran, spektrum vibrasi vitamin C

\section{Abstract}

Measurement of the vibrational spectrum of vitamin $C$ was carried out using Fourier Transform Infra Red Reflectance (ATR-FTIR) spectroscopy. Vitamin C has special absorption properties that represent as vitamin $C$ spectra. The vibrational spectrum shows the $C-H$ group bond, $C=O, C=C, C-O-C$, and $O-H$ groups. The result of measurement on the vitamin $C$ spectrum using force gauge showed a maximum absorbance was 0.0216 with the wavelength area was $1320.14 \mathrm{~cm}-1$. The results of the measurement of the spectrum of vitamin $C$ with a pressing time of 30 seconds showed a maximum absorbance is 0.0236 at the wavelength area was $1319.37 \mathrm{~cm}-1$. This study provided information for the measurement method using neutral FT-IR spectroscopy which measure spectroscopic spectra of FT-IR reflectance mode (ATR-FTIR) to characterize the research products. The method is a molecular vibration analysis technique for determining functional groups using reflectance FT-IR spectroscopy (ATR-FTIR) by comparing the reading spectrum of vitamin C-KBr samples and interpreting the resulting spectra.

Keywords: FTIR, measurement, reflectance method, vibrational spectrum of vitamin C

\section{Pendahuluan}

\subsection{Latar Belakang}

Peralatan analisis yang ada di laboratorium kimia FMIPA UNNES merupakan alat keluaran dari pabrikan di luar negeri, salah satunya adalah Perkin Elmer FT-IR Model : Frontier S/N : 96772, yang termasuk jenis peralatan kategori 3 yaitu peralatan yang cara pengoperasian dan perawatannya sulit, resiko penggunaan tinggi, akurasi / kecermatan pengukurannya tinggi, serta sistem kerja rumit sehingga pengoperasiannya memerlukan keahlian skill laboratorium yang baik. Spektrofotometer FTIR merupakan salah satu instrumen yang banyak digunakan untuk mengetahui spektrum vibrasi molekul yang dapat digunakan untuk memprediksi struktur senyawa kimia. Terdapat tiga teknik pengukuran sampel yang umum digunakan dalam pengukuran spektrum menggunakan FTIR yaitu
Photo Acoustic Spectroscopy (PAS), Attenuated Total Reflectance (ATR), dan Difuse Reflectance Infrared Fourier Transform (DRIFT). Setiap teknik memiliki karakteristik spektrum vibrasi molekul tertentu (Beasley et al., 2014).

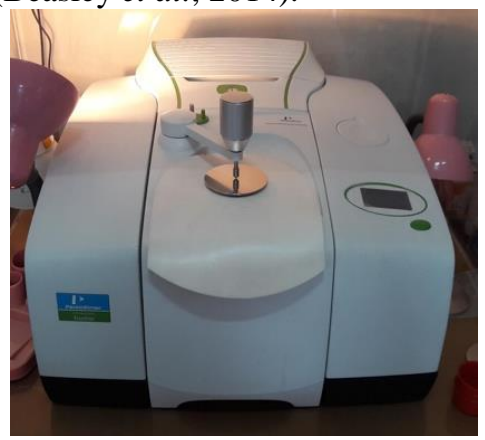

Gambar 1. Alat Perkin Elmer FT-IR: Frontier S/N : 96772 
Attenuated Total Reflektance (ATR-FTIR) adalah teknik cepat yang merupakan langkah awal yang berguna untuk mengkarakterisasi material. Kelebihan dari ATR adalah persiapan sampel yang tidak terlalu rumit, variasi spektrum lebih lebar karena persiapan sampel yang tidak terlalu rumit, dan tanpa menggunakan $\mathrm{KBr}$ grinding serta perbedaan ukuran partikel diabaikan (Thompson et al., 2009). ATR didasarkan pada fenomena refleksi internal total, dan mengukur perubahan yang terjadi dalam sinar inframerah yang dipantulkan internal dalam interaksi dengan sampel melalui Zink Selenium (ZnSe) kristal atau berlian (Bruno, 1999; Stathopoulou et al., 2008). Ketika sampel ditempatkan dalam kontak dengan kristal ATR, gelombang IR yang dihasilkan dilemahkan karena sampel menyerap energi (Bruno, 1999). Dengan tanpa mencampur sampel dengan $\mathrm{KBr}$ seperti pada teknik transmisi FTIR, sampel ditempatkan langsung pada pelat sampling diatas jendela optik dengan kristal ZnSe, kemudian ditahan oleh sebuah penjepit kompresi micrometer controlled untuk memastikan kontak yang baik antara sampel dan kristal.

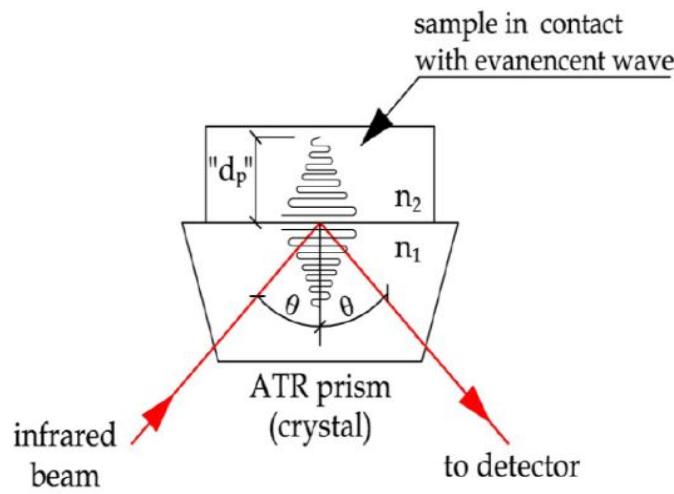

Gambar 2. Representasi sinar IR pada antarmuka prisma-sampel ATR-FTIR.

Spektrum vibrasi yang akan diinterprestasikan harus memenuhi beberapa syarat, diantaranya resolusi dan intensitas spektrum harus memadai, spektrum harus berasal dari zat murni, spektrofotometer harus dikalibrasi, serta teknik penyiapan sampel harus dijelaskan. Ketepatan kuat tekan, dan waktu penekanan dalam proses pengukuran sampel menggunakan FTIR metode reflektansi sangat menentukan hasil spektrum vibrasi sampel yang dihasilkan.

Data Badan Pusat Statistik Pangan (2015) memaparkan bahwa Indonesia memiliki tujuh jenis buah nusantara yang masuk dalam peringkat 20 besar sebagai negara produsen penghasil buah tingkat dunia. Ketujuh jenis buah nusantara itu adalah alpukat, pisang, pepaya, nenas, semangka, manggis, dan jambu biji. Pemberian nilai tambah pada buah nusantara menjadi hal yang sangat penting untuk segera dilakukan guna meningkatkan produksi, daya saing, dan nilai jual. Rendahnya kualitas, konsisten, dan keberlangsungan produksi buah nusantara sebagai akibat sistem pengusaha didominasi oleh sebagian besar petani perkebunan serta teknologi untuk menentukan kualitas produk juga masih sederhana.

Kualitas produk buah-buahan dapat ditentukan dari kandungan senyawa utamanya, yaitu berupa vitamin C. Vitamin C diisolasi dari buah yang memiliki sifat antioksidan tinggi kemudian dilanjutkan dengan proses identifikasi vitamin C dari spektrum vibrasinya (Levine, 1986). Pengukuran spektrum vibrasi vitamin $\mathrm{C}$ sejauh ini belum diteliti secara menyeluruh dikarenakan faktor kompleksitas yang tinggi dan simetri yang rendah (Singh et al., 2010). Salah satu teknik pengujian vitamin C dilakukan dengan penentuan spektrum vibrasi molekul menggunakan FTIR.

Berdasarkan latar belakang tersebut, penulis melakukan penelitian mengenai metode reflektansi (ATR-FTIR) pada pengukuran spektrum vibrasi vitamin $\mathrm{C}$ menggunakan FTIR dengan melakukan variasi kuat tekan dan waktu penekanan. Karakterisasi spektrum vibrasi vitamin C dilakukan menggunakan spektroskopi FTIR Spektrum 100 Perkin Elmer.

\subsection{Tujuan}

Tujuan penelitian ini adalah optimasi pengukuran spektrum vibrasi vitamin $\mathrm{C}$ menggunakan spektrofotometer Fourier Tarnsform Infra Red mode Reflektansi (ATR-FTIR) dengan melakukan variasi pengaruh kuat tekan dan pengaruh waktu penekanan terhadap spektrum vibrasi vitamin $\mathrm{C}$ yang dihasilkan.

\section{Metode Penelitian \\ 2.1 Alat dan Bahan}

Alat yang digunakan dalam penelitian ini adalah penggerus berupa lumpang dan alu, neraca analitik, spatula, cawan petri, dan Spektrofotometer FTIR Spektrum 100 Perkin Elmer Model: Frontier S/N: 96772. Sedangkan bahan yang digunakan dalam penelitian ini adalah vitamin $\mathrm{C}$ atau L-Ascorbic Acid, aceton, aquadest, lap pembersih/kim-wipe.

Sampel vitamin $\mathrm{C}$ atau L-Ascorbic Acid ditempatkan pada jendela optik diatas kristal $\mathrm{ZnSe}$ dan ditekan dengan variasi kuat tekan yaitu pada 10 , 20, 30, 40, 50, 60, 70, dan 80 (force gauge) untuk memastikan kontak yang baik antara sampel dan kristal. Pengujian dilakukan sesuai dengan SOP alat Spektrofotometer IR Spektrum 100 Perkin Elmer Model : Frontier S/N: 96772 dalam rentang bilangan gelombang $4000 \mathrm{~cm}^{-1}$ sampai $600 \mathrm{~cm}^{-1}$, dengan 10 kali pembacaan dan resolusi $8 \mathrm{~cm}^{-1}$. Spektrum yang dihasilkan dianalisis menggunakan 
perangkat lunak Spektrum Software FT-IR Perkin Elmer.

\subsection{Cara Kerja}

Optimasi waktu penekanan pada pengukuran sampel vitamin $\mathrm{C}-\mathrm{KBr}$ dilakukan dengan melakukan variasi waktu penekanan yaitu pada 15, 30, 45, 60, 75, 90, 105, 120, dan 135 (detik). Pengujian dilakukan sesuai dengan SOP alat Spektrofotometer IR Spektrum 100 Perkin Elmer Model : Frontier S/N: 96772 dalam rentang bilangan gelombang $4000 \mathrm{~cm}^{-1}$ sampai $600 \mathrm{~cm}^{-1}$, dengan 10 kali pembacaan dan resolusi $8 \mathrm{~cm}^{-1}$. Spektrum yang dihasilkan dianalisis menggunakan perangkat lunak Spektrum Software FT-IR Perkin Elmer.

\section{Hasil dan Pembahasan}

Sebelum melakukan pengujian sampel vitamin C menggunakan spektroskopi FTIR, terlebih dahulu dilakukan pengaturan mode reflektansi (ATR-FTIR) pada spektroskopi FTIR. Setelah mode reflektansi siap, maka dilakukan scan background. Sample vitamin C disiapkan diatas plat sample holder. Optimasi kuat tekan pengepresan pada pengukuran sampel vitamin $\mathrm{C}$ dilakukan dengan melakukan variasi kuat tekan yaitu pada 10, 20, 30, 40, 50, 60, 70 , dan 80 (force gauge). Tujuan pengepresan dilakukan agar sisi yang ditembak dengan sinar inframerah tidak terlalu tebal. Jika sisi yang ditembak dengan sinar inframerah terlalu tebal maka sinar inframerah juga akan terhambur dengan tidak optimal. Hal ini menyebabkan puncak-puncak yang terjadi pada spektra inframerah tidak akurat lagi dan puncaknya juga akan melebar.

Kuat tekan merupakan kapasitas dari suatu bahan atau struktur dalam menahan beban yang akan mengurangi ukurannya. Beberapa bahan akan patah pada batas tekan dan beberapa mengalami deformasi yang tidak dapat dikembalikan. Deformasi tertentu dapat dianggap sebagai batas kuat tekan, meski belum patah, terutama pada bahan yang tidak dapat kembali ke kondisi semula.

Dari hasil pengujian variasi kuat tekan pengepresan pada pengukuran sampel vitamin $\mathrm{C}$ didapatkan hasil berupa spektrum yang disajikan pada Gambar 3 dan spektra kuat tekan yang optimal disajikan pada Gambar 4.

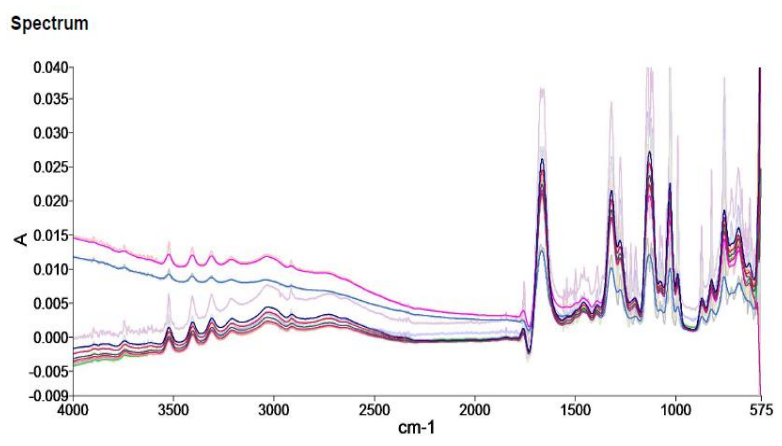

Gambar 3. Hasil spektrum IR variasi kuat tekan (10, $20,30,40,50,60,70,80$ force gauge ) pada pengukuran sample vitamin $\mathrm{C}$

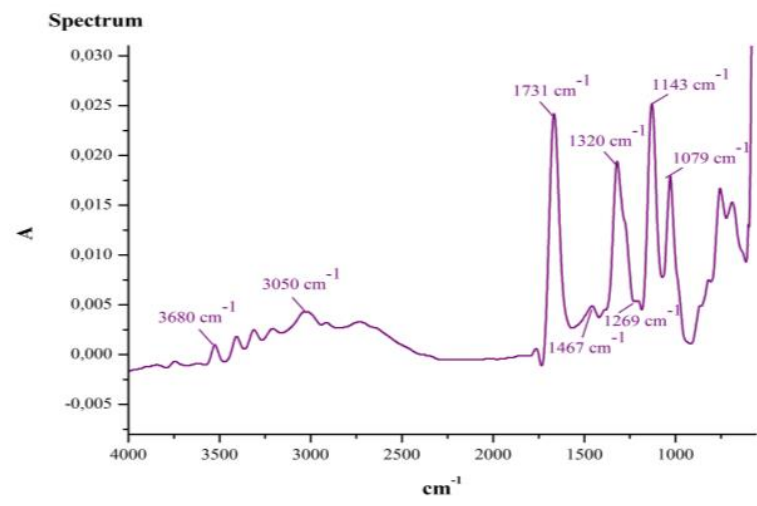

Gambar 4. Hasil spektrum IR variasi kuat tekan yang optimal (80 force gauge).

Gambar 3 menunjukkan spektrum vibrasi IR vitamin $\mathrm{C}$ yang dilakukan variasi kuat tekan 10,20,30,40,50,60,70,80 (force gauge). Gambar 4 menjelaskan bahwa pita serapan ikatan gugus $-\mathrm{OH}$ dan gugus $\mathrm{C}-\mathrm{H}$ pada semua sampel terlihat pada daerah bilangan gelombang $3680 \mathrm{~cm}^{-1}$ yang menunjukkan adanya vibrasi $-\mathrm{OH}$ dan pada daerah bilangan gelombang $3050 \mathrm{~cm}^{-1}$ yang menunjukkan adanya vibrasi $\mathrm{C}-\mathrm{H}$ dari vitamin $\mathrm{C}$. Pita serapan ikatan gugus $\mathrm{C}=\mathrm{C}$ terlihat pada daerah bilangan gelombang $1731 \mathrm{~cm}^{-1}$ dan $1079 \mathrm{~cm}^{-1}$. Pita serapan ikatan gugus $\mathrm{H}-\mathrm{C}-\mathrm{H}$ terlihat pada daerah bilangan gelombang $1467 \mathrm{~cm}^{-1}$. Pita serapan ikatan gugus $\mathrm{H}-$ C-O terlihat pada bilangan gelombang $1269 \mathrm{~cm}^{-1}$. Sementara ikatan gugus C-C pada daerah bilangan gelombang $1143 \mathrm{~cm}^{-1}$.

Gambar 4 juga menunjukkan pita serapan khas dari vitamin $\mathrm{C}$ yaitu adanya ikatan gugus $\mathrm{H}-\mathrm{O}-\mathrm{C}, \mathrm{H}-\mathrm{C}-$ $\mathrm{C}$, dan $\mathrm{C}-\mathrm{C}-\mathrm{C}-\mathrm{H}$ yang terlihat pada daerah bilangan gelombang $1320 \mathrm{~cm}^{-1}$ (Singh et al., 2007). Pada Gambar 3. terlihat bahwa spektrum IR dengan warna ungu menunjukkan puncak absorbansi yang tinggi sekitar 0,0216 A sehingga pada kuat tekan 80 force gauge menjadi kuat tekan yang optimal dari variasi kuat tekan pada proses pengukuran sampel vitamin C. Data pengukuran absorbansi variasi kuat 
tekan sampel vitamin C menggunakan spektroskopi FTIR metode reflektansi disajikan pada Tabel 1.

Tabel 1. Data Pengukuran Absorbansi Variasi Kuat Tekan Pengukuran Sampel Vitamin C Menggunakan Spektroskopi FTIR

\begin{tabular}{ccc}
\hline $\begin{array}{c}\text { Kuat tekan } \\
\text { (force gauge) }\end{array}$ & $\begin{array}{c}\text { Bilangan } \\
\text { gelombang }\left(\mathrm{cm}^{-1}\right)\end{array}$ & $\begin{array}{c}\text { Absorbance } \\
(\mathrm{A})\end{array}$ \\
\hline 10 & 1320.39 & 0.0010 \\
20 & 1320.32 & 0.0167 \\
30 & 1320.17 & 0,0160 \\
40 & 1320.16 & 0,0172 \\
50 & 1320.17 & 0,0177 \\
60 & 1320.21 & 0,0188 \\
70 & 1320.19 & 0,0202 \\
$\mathbf{8 0}$ & $\mathbf{1 3 2 0 . 1 4}$ & $\mathbf{0 , 0 2 1 6}$ \\
\hline
\end{tabular}

Optimasi waktu penekanan pada pengukuran sampel vitamin $\mathrm{C}$ dilakukan dengan melakukan variasi waktu penekanan yaitu pada 15, 30, 45, 60, 75, 90, 105, 120, dan 135 (detik). Dari hasil pengujian variasi waktu penekanan pada pengukuran sampel vitamin $\mathrm{C}$ didapatkan hasil berupa spektra masingmasing variasi yang disajikan pada Gambar 5 dan variasi waktu penekanan yang optimal disajikan pada Gambar 6.

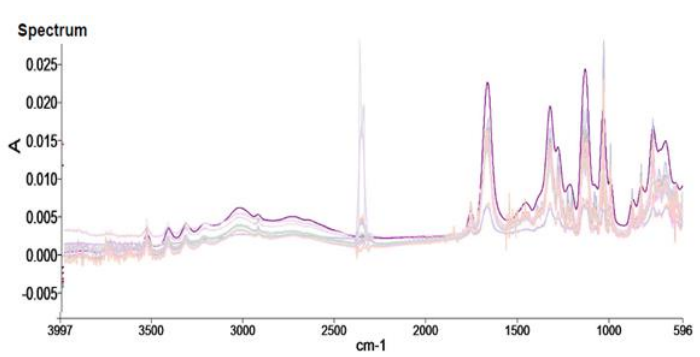

Gambar 5. Hasil spektrum IR variasi waktu penekanan $(15,30,45,60,75,90,105,120,135,150$ detik) pada pengukuran sampel vitamin $\mathrm{C}$.

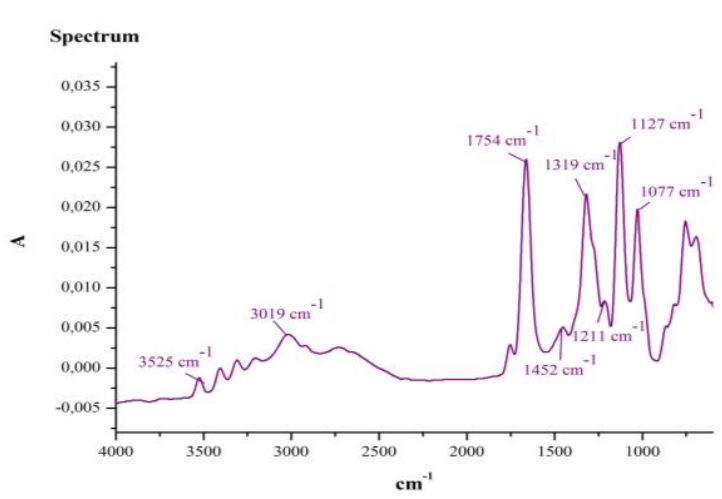

Gambar 6. Hasil spektrum IR variasi waktu penekanan yang optimal (30 detik)

Gambar 5 menunjukkan spektrum vibrasi IR vitamin $\mathrm{C}$ yang dilakukan variasi waktu penekanan pada $15,30,45,60,75,90,105,120$, dan 135 (detik). Gambar 6 menjelaskan bahwa pita serapan ikatan gugus $\quad-\mathrm{OH}$ dan gugus $\mathrm{C}-\mathrm{H}$ pada semua sampel terlihat pada bilangan gelombang $3525 \mathrm{~cm}^{-1}$ yang menunjukkan adanya vibrasi $-\mathrm{OH}$ dan pada daerah bilangan gelombang $3019 \mathrm{~cm}^{-1}$ yang menunjukkan adanya vibrasi $\mathrm{C}-\mathrm{H}$ dari vitamin $\mathrm{C}$. Pita serapan ikatan gugus $\mathrm{C}=\mathrm{C}$ terlihat pada daerah bilangan gelombang $1754 \mathrm{~cm}^{-1}$ dan $1077 \mathrm{~cm}^{-1}$. Pita serapan ikatan gugus $\mathrm{H}-\mathrm{C}-\mathrm{H}$ terlihat pada daerah bilangan gelombang $1452 \mathrm{~cm}^{-1}$. Pita serapan ikatan gugus $\mathrm{H}-\mathrm{C}-\mathrm{O}$ terlihat pada bilangan gelombang $1211 \mathrm{~cm}^{-1}$. Sementara ikatan gugus C-C pada daerah bilangan gelombang $1127 \mathrm{~cm}^{-1}$.

Gambar 6 juga menunjukkan pita serapan khas dari vitamin $\mathrm{C}$ yaitu adanya ikatan gugus $\mathrm{H}-\mathrm{O}-\mathrm{C}, \mathrm{H}-\mathrm{C}-$ $\mathrm{C}$, dan $\mathrm{C}-\mathrm{C}-\mathrm{C}-\mathrm{H}$ yang terlihat pada daerah bilangan gelombang $1319 \mathrm{~cm}^{-1}$ (Singh et al., 2007). Pada Gambar 5 terlihat bahwa spektrum IR dengan warna ungu menunjukkan puncak absorbansi yang tinggi sekitar 0,0236 A sehingga pada waktu penekanan 30 detik menjadi waktu yang optimal dari variasi waktu penekanan pada proses pengukuran sampel vitamin C. Data pengukuran absorbansi variasi waktu penekanan sampel vitamin $\mathrm{C}$ menggunakan spektroskopi FTIR disajikan pada Tabel 2.

Tabel 2. Data Pengukuran Absorbansi Variasi Waktu Penekanan Pengukuran Sampel Vitamin C Menggunakan Spektroskopi FTIR

\begin{tabular}{ccc}
\hline $\begin{array}{c}\text { Waktu } \\
\text { penekanan } \\
\text { (detik) }\end{array}$ & $\begin{array}{c}\text { Bilangan } \\
\text { gelombang }\left(\mathrm{cm}^{-}\right.\end{array}$ & $\begin{array}{c}\text { Absorbance } \\
\text { (A) }\end{array}$ \\
\hline 15 & 1319.74 & 0.0041 \\
$\mathbf{3 0}$ & $\mathbf{1 3 1 9 . 3 7}$ & $\mathbf{0 . 0 2 3 6}$ \\
45 & 1319.53 & 0.0157 \\
60 & 1319.77 & 0.0132 \\
75 & 1319.71 & 0.0137 \\
90 & 1320.03 & 0.0114 \\
105 & 1320.21 & 0.0121
\end{tabular}




\begin{tabular}{lll}
120 & 1320.17 & 0.0128 \\
135 & 1320.10 & 0.0128 \\
150 & 1319.79 & 0.0127 \\
\hline
\end{tabular}

Hasil penelitian terkait spektrum vibrasi vitamin C dari variasi kuat tekan maupun variasi waktu penekanan ini telah sesuai Panicker et al., (2006) yang melakukan penelitian terkait struktural dan getaran komprehensif molekul vitamin C (LAscorbic Acid) . Gambar struktur vitamin C disajikan pada Gambar 7.<smiles>C[C@]1([C@@H](O)CO)OC(=O)C(=O)C1=O</smiles>

Gambar 7. Struktur vitamin C (L-Ascorbic Acid)
Singh, G., S. Kaur, \& G.S.S. Saini. 2007. Experimental and Theoretical Vibrational Analysis of Vitamin C. Indian Journal of Pure \& Applied Physics 45: 714-720.

Singh, P., N. P. Singh, \& R. A. Yadav. 2010. Study of the optimized molecular structures and vibrational characteristics of neutral L-Ascorbic acid and its anion and cation using density functional theory. Journal of Chemical and Pharmaceutical Research 2(5): 656-681.

Stathopoulou, E. T., V. Psycharis, G. D. Chryssikos, V. Gionis, \& G. Theodorou. 2008. Bone diagenesis: new data from infrared spectroscopy and X-ray diffraction. Palaeogeography Palaeoclimatology Palaeoecology 266(3): 168-174.

Thompson, T.J.U., M. Gauthier, \& M. Islam. 2009. The application of a new method of Fourier Transform Infrared Spectroscopy to the analysis of burned bone. Journal of Archaeological Science 36(3): 910-914.

\section{Kesimpulan}

Berdasarkan hasil penelitian pengukuran spektrum vibrasi vitamin $\mathrm{C}$ menggunakan Spektrofotometer Fourier Transform Infra Red (FT-IR) metode Reflektansi (ATR-FTIR) diperoleh simpulan bahwa kuat tekan dan waktu penekanan sangat berpengaruh terhadap spektrum vibrasi vitamin $\mathrm{C}$ yang dihasilkan, dengan kuat tekan optimal sebesar 80 (force gauge) dan waktu penekanan yang optimal sebesar 30 dalam satuan detik.

\section{Daftar Pustaka}

Beasley, M. M., E. J. Bartelink, L. Tailor, \& R. M. Miller. 2014. Comparison of transmission FTIR, ATR, and DRIFT spectra: implications for assessment of bone bioapatite diagenesis. Journal of Archaeological Science 46: 16-22.

Bruno, T. J. 1999. Sampling Accessories for Infrared Spectrometry. Applied Spectroscopy Reviews 34(1\&2): 91-120.

Levine, M., \& M.D. 1986. New Consepts in the Biology and Biochemistry of Ascorbic Acid. Seminar in Medicine of the Beth Israel Hospital. Israel: Boston.

Panicker, C.Y., H. T. Varghese, \& D. Philip. 2006. FT-IR, FT-Raman and SERS spectra of Vitamin C. Spectrochimica Acta Part A 65: 802-804. 